\title{
Illusions of Team Working in Health Care
}

\section{Viewpoint Paper}

\author{
Michael A. West \\ Lancaster Management School \\ Lancaster University \\ M.A.West@lancaster.ac.uk \\ Joanne Lyubovnikova \\ Aston Business School \\ Aston University \\ J.Lyubovnikova@aston.ac.uk
}

This paper should be referenced as follows:

West, M.A., \& Lyubovnikova, J. (2013). Illusions of Team Working in Health Care. Journal of Health Organization and Management, 27(1), 134-142. 


\begin{abstract}
Purpose: The ubiquity and value of teams in healthcare are well acknowledged. However, in practice, healthcare teams vary dramatically in their structures and effectiveness in ways that can damage team processes and patient outcomes. This paper highlights these characteristics and extrapolates several important aspects of teamwork which have a powerful impact on team effectiveness across healthcare contexts.
\end{abstract}

Design/methodology/approach: We draw upon the literature from health services management and organisational behaviour to provide an overview of the current science of healthcare teams.

Findings: Underpinned by the Input-Process-Output framework of team effectiveness, team composition, team task, and organisational support are viewed as critical inputs that influence key team processes including team objectives, leadership and reflexivity, which in turn impact staff and patient outcomes. Team training interventions and care pathways can facilitate more effective interdisciplinary teamwork.

Originality/value: The paper argues that the prevalence of the term 'team' in healthcare makes the synthesis and advancement of the scientific understanding of healthcare teams a challenge. Future research therefore needs to better define the fundamental characteristics of teams in studies in order to ensure we can accumulate findings based on real teams, rather than pseudo-like groups.

Keywords: Teams, teamwork, team effectiveness, collaboration, team processes, patient safety, errors. 


\section{Background}

The imperative for effective intra and inter-team collaboration has become increasingly prioritised in healthcare policy both nationally (Darzi, 2008) and internationally (Joint Commission, 2009). This is because a large body of research evidence suggests that effective teamwork in healthcare is associated with reduced medical errors (Manser, 2009), increased patient safety (Firth-Cozens, 2001), as well as improved worker outcomes such as reduced stress (Carter and West, 1999), intent to stay at work (Abualrub et al., 2012), and job satisfaction (Buttigieg et al., 2011). Other studies have also found that the quality of teamwork in healthcare is related to patient mortality in hospitals (West et al., 2001), more streamlined and cost effective patient care (Ross et al., 2000), reduced physician visits and hospitalisation rates (Sommers et al., 2000), lower staff absenteeism and turnover, more effective use of resources and greater patient satisfaction (West et al., 2011).

Most healthcare organisations operate in a complex context of conflicting demands and objectives, multi-faceted and often highly challenging daily tasks, a demanding external environment, and a highly diverse body of professional clinical staff (Ramanujam and Rousseau, 2006). Therefore, as patients' progress along the care pathway, the delivery of effective healthcare very much depends on the careful collaboration and interchange of information between various individuals, organisations, occupational groups, multidisciplinary teams, and allied health services. Whatever changes are occurring in healthcare systems both nationally and internationally, it is important to reflect on why effective healthcare teams are so important in health service delivery, and how team processeswe can be improved to ensure we are delivering high quality and safe patient care. The fact is that healthcare teams are very often ineffective with research showing that $70 \%$ of medical errors can be attributed to poor teamwork (Studdert et al., 2002). Organisations 
therefore need advice on how to develop authentic and effective teamwork which facilitates a culture for safety and quality, rather than relying on the dangerous illusion that simply labelling a group of healthcare professionals a 'team' will produce the coordination, clear role allocation and powerful shared responsibility the notion of 'teamwork' implies.

\section{A Typology of Healthcare Teams}

Despite the prevalence of healthcare teams, when we look more closely at their nature and characteristics, there are many notable divergences and complexities that should be recognised. A useful typology for describing teams proposed by Hollenbeck et al. (2012) enables teams to be characterised on three underlying dimensions. Firstly, teams differ on skill differentiation. Traditionally healthcare teams were unidisciplinary (for example, a team of paediatric nurses working on a hospital ward), meaning that team members held very similar functional knowledge and conducted similar clinical tasks. However, healthcare teams are now increasingly interdisciplinary. Interdisciplinary teams comprise members from different functional and clinical backgrounds working towards shared goals, in order to fulfil complex and interdependent tasks which require varying degrees of specialist skills and medical knowledge.

Secondly, healthcare teams can be distinguished on the dimension of authority differentiation (Hollenbeck et al., 2012), which describes the extent to which all team members are involved in team decision making processes. Healthcare teams with high levels of authority differentiation have clearly allocated leadership roles, which tend to be occupied by the most senior status member of a team. However, the prevalence of entrenched hierarchies and deep rooted conflict amongst professionals in healthcare (Leape and Berwick, 2005), means that decision making is often faulty, undermining high quality and safe care. 
Unidisciplinary teams on the other hand tend to have lower authority differentiation, given the more equal status held by respective team members.

The third teamwork dimension proposed by Hollenbeck et al. (2012) is temporal stability. Whereas some healthcare teams maintain a relatively stable team composition over time (such as a multidisciplinary team members working together over several years), other teams may be formed temporarily to act as a 'one shot' team (to conduct a highly novel

surgical procedure for example), and therefore team members may never work together again. Teams with higher levels of temporal stability have the opportunity to develop effective team processes, given the familiarity that develops between members of the team.

Thus, when researching and managing healthcare teams, it is important to pay attention to the structural dimensions of skill differentiation, autonomy differentiation and temporal stability and how they impact upon team functioning and performance. For example, research with staff nurses in 32 hospitals in England found that teamwork and autonomy were highly related, and that nursing autonomy was associated with increased job satisfaction and more positive perceptions of quality of care (Rafferty et al., 2001). Temporal stability is also crucial for the development of shared mental models and effective interpersonal team processes, which in turn affect care processes (Richardson et al., 2010). Thus, healthcare researchers and practitioners cannot afford to neglect such important structural features of healthcare teams.

\section{Key Debates in Teams Research}

The use of teams to deliver health care has become commonplace in the English National Health Service (NHS), with recent findings from the NHS National Staff Survey suggesting that over $90 \%$ of staff report that they work in 'a team' (Care Quality Commission, 
2010). However, this creates challenges for researching real teams, as only around $40 \%$ of staff report that their team has clear shared objectives, works closely and interdependently, and reviews its effectiveness on a regular basis - all fundamental features of what defines a team in the first place (see Figure 1; West et al., 2012). Without these 'real team' characteristics in place, a team exists in name only. Such pseudo team entities not only deviate from theoretical definitions of real teams in the literature, but can also be associated with potentially detrimental outcomes in practice. Indeed, members of pseudo teams report witnessing higher levels of errors, incidents and near misses, experience more harassment, bullying and abuse from staff and patients, and report lower levels of well-being and higher stress than members of real teams (West et al., 2012). So how can we be clearer about teamwork in healthcare both theoretically and in practice?

\section{The Science of Teams in Healthcare}

The most widely accepted framework for conceptualising teams is the Input-ProcessModel (IPO) of team effectiveness (Cohen and Bailey, 1997). This framework proposes that team inputs (such as team composition, the team task, resources, and organisational support) have an influence on team outputs (such as error rates, quality of care, patient satisfaction, and team member well-being) via the interactions or team processes that take place between team members. Over the years, a number of both generic and context specific IPO models of healthcare team effectiveness have been published in the literature (e.g. Lemieux-Charles and McGuire, 2006). Based on our own research, below we outline what we consider are the three most important inputs and processes for predicting performance of healthcare teams (see Figure 2).

\section{Inputs}


Team task - All teams require a team task. If a task is insufficiently complex that it could just as well be conducted by an individual working in isolation, then a team is not necessary in the first place. In fact, assigning teams to overly simplistic tasks can be detrimental to organisational performance, given the process losses that are inherent in working groups (e.g. social loafing, diffusion of responsibility). Healthcare teams therefore should be used for relatively complex tasks that require some degree of task interdependence - in short, that require teamwork. Task interdependence defines the extent of task driven interaction among team members; in other words this is the degree to which team members depend on one another for both individual and team task completion. Task interdependence is not only determined by the characteristics of the team task itself, but also by the extent of discretion that team members exercise in establishing the level of interaction and cooperation required for effective performance (Shea and Guzzo, 1987). Team members therefore must decide to behave together interdependently - to work as a team.

Team composition - Teams must be composed of individuals who together have the appropriate knowledge, skills and abilities (KSAs) to complete the team task successfully. For example, an effective community mental health team requires a diverse pool of KSAs from various professional groups (e.g. psychiatrists, clinical psychologists, psychiatric nurses, social workers, occupational therapists) who collectively form a multi-professional team. If any one of these required disciplines is missing from the team composition, decision making processes are likely to be dysfunctional, and in turn, patient care will suffer. Conversely, if the team is too large, and there are multiple occupiers of the same specialist role, team members may compete for power or withdraw their participation from the team. Team size should therefore be appropriate for the team task demands, and should typically not exceed 8 to 12 members (West, 2012). 
Organisational Support - Crucially, at the organisational level, the context within

which healthcare teams are embedded must support team-based working. Team, rather than individual, efforts should be acknowledged through a reward system which encourages team members to work collaboratively and recognises their task interdependence.

\section{Processes}

Team Objectives - Teams are fundamentally defined by their shared objectives.

Therefore, a key team process involves team members agreeing upon a number of specific team objectives which will guide teamwork behaviour. Team objectives are critical as they give team members the incentive to combine their efforts and collaborate closely. Research has shown that primary care teams with clear goals performed better on patient-perceived quality and patient satisfaction than those without (Goñi, 1999). Poulton and West (1999) also found that clarity of and commitment to team objectives was the best predictor of manager ratings of team effectiveness of primary health care teams. However, our own research consistently shows that it is common for team members to be unclear about exactly what the objectives of the team are, thereby making interdependent working more difficult. Objectives should be clear, challenging, agreed upon, measurable, and limited to no more than six to eight in number (West, 2012)

Leadership - Evidence suggests that leadership makes a significant difference to the performance of healthcare teams. However, given that entrenched professional tensions, status incongruities and boundary disputes are typical in interdisciplinary teams, it is no surprise that leadership is often poor (Ovretveit, 2002). In an analysis of nearly 300 healthcare teams (including primary health care teams, cancer teams, and community mental health teams), West (2003) concluded that when there was conflict about leadership within 
the team, both team processes and outcomes were negatively affected. Just one tenth of community mental health teams and one third of primary health care teams reported having a clear leader. Conversely, leadership clarity was associated with high levels of participation, clear team objectives, commitment to excellence and support for innovation, which in turn consistently predicted team innovation in patient care.

Reflexivity - Reflexivity is the extent to which teams regularly take time out to define

what it is they are trying to achieve, how well they are working, what they need to change, and then making adjustments accordingly (Widmer et al., 2009). Reflexivity is crucial for healthcare teams, as it enables them to reflect upon the suitability of their objectives to ensure that these are aligned with patient needs and emerging organisational challenges. Empirical evidence has shown that reflexivity in healthcare teams is an important determinant of effective team functioning (Carter and West, 1998). Given that reflexive teams build selfawareness, they are also more likely to recognise areas that need attention and development, and implement necessary improvement plans (Tjosvold et al., 2004). However, in a study of 250 health care team members, Wiles and Robison (1994) found that only a quarter of teams reported holding regular team meetings, with the remainder of teams only meeting if there was a specific problem to be resolved. Team leaders' responsibility is therefore to ensure regular team reflexivity, given the clear associations with improved individual and organisational outcomes in healthcare (West et al., 2012).

\section{Interventions to Promote Teamwork in Healthcare}

A common method for enhancing the effectiveness of teamwork in healthcare is the provision of team training. Examples include the 'TeamSTEPPS' (Team Strategies and Tools to Enhance Performance and Patient Safety) program developed by the Agency for 
Healthcare Research and Quality (AHRQ) in the United States which focuses on developing four team competencies; communication, leadership, mutual support and situation monitoring (Baker et al., 2010); the Aston Team Facilitation Programme (ATFP; Aston Organisation Development, 2003) which is widely used in the NHS; and the more generic SBAR (situation, background, assessment, recommendation) tool which can lead to improved team communication and patient safety (Leonard et al., 2004).

A specific intervention which has also been linked to improving interdisciplinary teamwork is care pathways. Care pathways are defined as 'a complex intervention for the mutual decision making and organization of care for a well-defined group of patients during a well-defined period' (Vanhaecht et al., 2010, p.118) In a systematic review of 27 studies, Deneckere et al., (2012) concluded that care pathways can promote various facets of team working including team communication, team relations, inter-professional documentation and staff knowledge. Such high-performance work systems impact organisational performance by strengthening action and interpersonal processes, including coordination and communication (Gittell et al., 2010).

\section{Future Research Agenda}

Based on research evidence that highlights the detrimental impact of pseudo team working on outcomes, future research into healthcare teams should first endeavour to better describe team samples according to the fundamental characteristics of real teams (West and Lyubovnikova, 2012). Such characteristics are crucial if health care staff are to effectively combine their diverse professional perspectives, coordinate efforts and share knowledge in order to deliver highly complex clinical tasks; yet they are very often neglected in healthcare teams research to date. Further, given that healthcare delivery is embedded in a complex multi-team system that requires both inter-team and inter-team working (Bleakley, 2012), future research should not only focus on effective collaboration within teams, but also 
between teams. Healthcare professionals are often members of several teams concurrently, making the concept of multiple team membership (O'Leary et al., 2011) increasingly relevant to future healthcare research. 


\section{References}

Abualrub, R.F., Gharaibeh, H.F. and Bashayreh, A.E.I. (2012), “The relationships between safety climate, teamwork, and intent to stay at work among Jordanian hospital nurses," Nursing Forum, Vol. 47 No. 1, pp. 65-75.

Aston Organisation Development. (2003), Aston Team Facilitation Programme, Farnham, Surrey, UK.

Baker, D.P., Amodeo, A.M., Krokos, K.J., Slonim, A. and Herrera, H. (2010), “Assessing teamwork attitudes in healthcare: development of the TeamSTEPPS teamwork attitudes questionnaire," Quality and Safety in Health Care, Vol. 19 No. 6, pp. 1-4.

Bleakley, A. (2012), “Working in 'teams' in an era of 'liquid' healthcare: What is the use of theory?" Journal of Interprofessional Care, Early Online, pp.1-9.

Buttigieg, S.C., West, M.A. and Dawson, J.F. (2011), "Well-structured teams and the buffering of hospital employees from stress," Health Services Management Research, Vol. 24 No. 4, pp. 203-12.

Care Quality Commission. (2010), “NHS staff survey 2010,” Retrieved from http://webarchive.nationalarchives.gov.uk/20110718105843/http:/www.cqc.org.uk/abou tcqc/howwedoit/engagingwithproviders/nhsstaffsurveys/staffsurvey2010.cfm. 
Carter, A.J. and West, M.A. (1999), "Sharing the burden: Teamwork in health care settings," In Firth-Cozens, J. and Payne, R. (Eds.), Stress in health professionals: Psychological causes and interventions., Chichester, UK, Wiley, pp. 191-202.

Carter, S.M. and West, M.A. (1998), "Reflexivity, Effectiveness, and Mental Health in BBCTV Production Teams," Small Group Research, Vol. 29 No. 5, pp. 583-601.

Cohen, S.G. and Bailey, D.E. (1997), "What Makes Teams Work: Group Effectiveness Research from the Shop Floor to the Executive Suite," Journal of Management, Vol. 23 No. 3, pp. 239-290.

Darzi, Lord. (2008), High quality care for all: NHS Next Stage Review, London, Department of Health.

Deneckere, S., Euwema, M., Van Herck, P., Lodewijckx, C., Panella, Massimiliano, Sermeus, Walter and Vanhaecht, Kris. (2012), "Care pathways lead to better teamwork: results of a systematic review," Social Science \& Medicine, Vol. 75 No. 2, pp. 264-268.

Firth-Cozens, J. (2001), "Cultures for improving patient safety through learning: the role of teamwork," Quality in Health Care, Vol. 10 Suppl 2, pp. ii26-31.

Gittell, J.H., Seidner, R. and Wimbush, J. (2010), “A relational model of how high performance work systems work," Organization Science, Vol. 21, pp. 490-506. 
Goñi, S. (1999), “An analysis of the effectiveness of Spanish primary health care teams," Health Policy, Vol. 48 No. 2, pp. 107-117.

Hollenbeck, J.R., Beersma, B. and Shouten, M.E. (2012), "Beyond team types and taxonomies: A dimensional scaling conceptualization for team description," Academy of Management Review, Vol. 37, pp. 82-106.

Joint Commission. (2009), "Patient safety goals," Retrieved from http://www.jointcommission.org/standards_information/npsgs.aspx

Leape, L.L. and Berwick, D.M. (2005), "Five years after To Err Is Human: what have we learned?” The Journal of the American Medical Association, Vol. 293 No. 19, pp. 238490.

Lemieux-Charles, L. and McGuire, W.L. (2006), "What do we know about health care team effectiveness? A review of the literature," Medical Care Research and Review, Vol. 63 No. 3, pp. 263-300.

Leonard, M., Graham, S. and Bonacum, D. (2004), “The human factor: the critical importance of effective teamwork and communication in providing safe care," Quality and Safety in Health Care, Vol. 13 Suppl 1 pp. i85-90.

Manser, T. (2009), “Teamwork and patient safety in dynamic domains of healthcare: a review of the literature," Acta anaesthesiologica Scandinavica, Vol. 53 No. 2, pp. 143-51. 
Ovretveit, J. (2002), "Quality collaboratives: lessons from research,” Quality and Safety in Health Care, Vol. 11 No. 4, pp. 345-351.

O’Leary, M.B., Mortensen, M. and Woolley, A.W. (2011), "Multiple team membership: a theoretical model of its effects on productivity and learning for individuals and teams," Academy of Management Review, Vol. 36 No. 3, pp. 461-478.

Poulton, B.C. and West, M. A. (1999), “The determinants of effectiveness in primary health care teams," Journal of Interprofessional Care, Vol. 13 No. 1, pp. 7-18.

Rafferty, A.M., Ball, J. and Aiken, L.H. (2001), “Are teamwork and professional autonomy compatible, and do they result in improved hospital care?" Quality and Safety in Health Care, Vol. 10 No. Supplement 2, p. ii32-ii37.

Ramanujam, R. and Rousseau, D.M. (2006), “The challenges are organizational not just clinical," Journal of Organizational Behavior, Vol. 27 No. 7, pp. 811-827.

Richardson, J., West, M.A. and Cuthbertson, B.H. (2010), “Team working in intensive care: current evidence and future endeavors," Current Opinion in Critical Care, Vol. 16 No. 6, pp. 643-648.

Ross, F., Rink, E. and Furne, A. (2000), "Integration or pragmatic coalition? An evaluation of nursing teams in primary care," Journal of Interprofessional Care, Vol. 14 No. 3, p. 259-267. 
Shea, G.P. and Guzzo, R.A. (1987), “Groups as Human Resources,” In Rowland, K.M.,

Ferris, G.R. (Eds,), Research in Personnel and Human Resource Management, Greenwich, CT, JAI Press, Vol 5, pp. 323-356.

Sommers, L.S., Marton, K.I., Barbaccia, J.C. and Randolph, J. (2000), "Physician, Nurse, and

Social Worker Collaboration in Primary Care for Chronically Ill Seniors," Archives of Internal Medicine, Vol. 160 No. 12, pp. 1825-1833.

Studdert, D.M., Brennan, T.A. and Thomas, E.J. (2002), "What have we learned from the Harvard Medical Practice Study?," In Rosenthal, M.M. and Sutcliffe, K.M. (Eds.), Medical Error: What Do We Know? What Do We Do?, San Francisco, Jossey Bass, pp. 3-33.

Tjosvold, D., Tang, M.M.L. and West, M. (2004), "Reflexivity for Team Innovation in China:

The Contribution of Goal Interdependence," Group \& Organization Management, Vol.

29 No. 5, pp. 540-559.

Vanhaecht, K., Panella, M., van Zelm, R. and Sermeus, W. (2010), “An overview on the history and concept of care pathways as complex interventions," International Journal of Care Pathways, Vol. 14 No. 3, pp. 117-123.

West, M. (2003), "Leadership clarity and team innovation in health care," The Leadership Quarterly, Vol. 14 No. 4-5, pp. 393-410. 
West, M.A., Borrill, C., Dawson, J., Scully, J., Carter, Matthew, Anelay, S., Patterson, M., et al. (2001), "The link between the management of employees and patient mortality in acute hospitals," The International Journal of Human Resource Management, Vol. 13 No. 8, pp. 1299-1310.

West, M.A. (2012), Effective Teamwork: Practical Lessons from Organizational Research, Oxford, Blackwell Publishing, 3rd Edition.

West, M.A., Dawson, J.F., Admasachew, L. and Topakas, A. (2011), “NHS Staff Management and Health Service Quality: Results from the NHS Staff Survey and Related Data," Retrieved from http://www.dh.gov.uk/health/2011/08/nhs-staffmanagement/

West, M.A., Dawson, J.F., Lyubovnikova, J. and Carter, M. (2012), “24-Karat or fool's gold? Consequences of authentic and pseudo team membership in healthcare organizations," Manuscript in preparation.

West, M.A. and Lyubovnikova, J. (2012), "Real Teams or Pseudo Teams? The Changing Landscape Needs a Better Map," Industrial and Organizational Psychology, Vol. 5 No. 1, pp. 25-28.

Widmer, P., Schippers, M. and West, Michael. (2009), "Recent developments in reflexivity research: A review," Psychology of Everyday Activity, Vol. 2 No. 2, pp. 2-11. 
Wiles, R. and Robison, J. (1994), “Teamwork in primary care: the views and experiences of nurses, midwives and health visitors," Journal of Advanced Nursing, Vol. 20 No. 2, pp. 324-330. 
Figure 1: Characteristics of Real and Pseudo Healthcare Teams

\begin{tabular}{|l|l|l|}
\hline Pseudo Teams & Team Characteristics & Real Teams \\
\hline $\begin{array}{l}\text { Healthcare team members work } \\
\text { largely on their own, with little } \\
\text { requirement to interact or } \\
\text { communicate with each other }\end{array}$ & Interdependence & $\begin{array}{l}\text { Healthcare team members work } \\
\text { closely together in a tightly } \\
\text { coordinated way }\end{array}$ \\
\hline $\begin{array}{l}\text { The objectives which healthcare team } \\
\text { members report their team is working } \\
\text { towards are largely disparate and/or } \\
\text { unknown }\end{array}$ & Shared Objectives & $\begin{array}{l}\text { Healthcare team members share } \\
\text { several common objectives which are } \\
\text { clear and agreed upon in the team }\end{array}$ \\
\hline $\begin{array}{l}\text { Healthcare team members rarely } \\
\text { meet together to exchange } \\
\text { information and reflect on } \\
\text { performance, resulting in little or no } \\
\text { innovation in care processes }\end{array}$ & Reflexivity & $\begin{array}{l}\text { Healthcare team members regularly } \\
\text { and systematically review their } \\
\text { performance and adapt future team } \\
\text { objectives and care processes } \\
\text { accordingly }\end{array}$ \\
\hline
\end{tabular}


Figure 2: An IPO Model of Healthcare Team Effectiveness
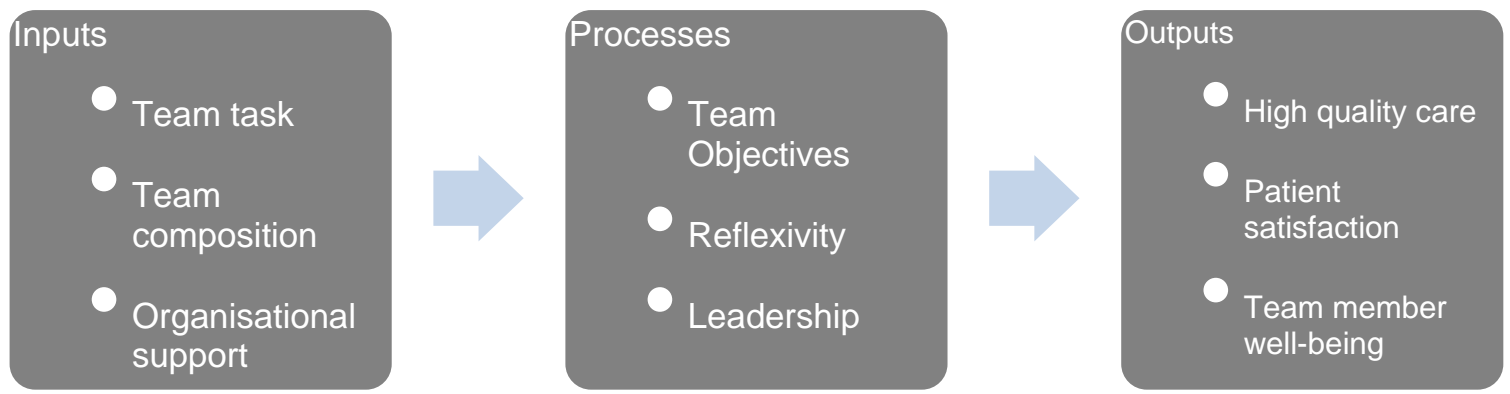


\section{Authors Details}

Professor Michael West is Professor of Work and Organisational Psychology at Lancaster University Management School, Senior Research Fellow at The Work Foundation and Emeritus Professor at Aston University. He graduated from the University of Wales in 1973 and received his $\mathrm{PhD}$ in 1977. He has published over 200 articles for scientific and practitioner publications, as well as multiple books and book chapters. His areas of research interest are team and organisational innovation and effectiveness, particularly in relation to the organisation of health services. He lectures widely both nationally and internationally about the results of his research and his solutions for developing effective and innovative organisations.

Dr Joanne Lyubovnikova is a Lecturer in Work and Organisational Psychology at Aston University. She graduated with a BSc (Hons) in Social Psychology from Loughborough University (2005) and an MSc in Work and Organisational Psychology from Aston University (2006), before receiving her PhD (2010), also from Aston University. Her PhD research focused on the prevalence and measurement of real teams in organisations. Joanne has been involved in a number of large scale research projects examining team working in the English National Health Service. Her research interests focus on the antecedents of team effectiveness, particularly in relation to diversity, engagement and virtual team working. 